\title{
TINGKAT KEPUASAN PASIEN TERHADAP PELAYANAN KEFARMASIAN DI RSUD Dr. MURJANI SAMPIT
}

\section{The Level of Patient Satisfaction to Pharmaceutical Service in Dr. Murjani Hospital Sampit}

\author{
*Susi Novaryatiin, Syahrida Dian Ardhany, \& Siti Aliyah
}

Department of Pharmacy, Faculty of Health Science, Universitas Muhammadiyah Palangkaraya, RTA. Milono St. Km. I.5 Palangka Raya, Indonesia

*e-mail : susi_novaryatiin@yahoo.com

\begin{abstract}
ABSTRAK
Pelayanan kefarmasian yang baik adalah pelayanan yang berorientasi langsung dalam proses penggunaan obat bertujuan menjamin keamanan, efektifitas dan kerasionalan penggunaan obat dengan menerapkan ilmu pengetahuan dan fungsi dalam perawatan pasien. Kepuasan konsumen adalah tanggapan pelanggan atau pengguna jasa untuk setiap pelayanan yang diberikan. Tujuan dari penelitian ini adalah untuk mengetahui tingkat kepuasan pasien terhadap pelayanan kefarmasian di RSUD Dr. Murjani Sampit. Metode yang digunakan dalam penelitian ini adalah metode deskriptif. Tingkat kepuasan diukur berdasarkan lima dimensi kualitas jasa, dan dianalisis dengan menggunakan persentase dan skala likert. Hasil penelitian menunjukkan rata-rata persentase interpretasi skor sebesar $68 \%$ yang artinya masuk dalam kategori puas.
\end{abstract}

Kata kunci: Tingkat kepuasan, pelayanan kefarmasian, RSUD Dr. Murjani Sampit

\begin{abstract}
Good pharmaceutical services are directly oriented services in the drug use process aimed at ensuring the safety, effectiveness and rationality of drug use by applying science and function in patient care. Consumer satisfaction is the response of customer or service user for each service provided. The purpose of this study was to determine the level of patient satisfaction to pharmaceutical service in RSUD Dr. Murjani Sampit. This study was conducted using descriptive method. The level of satisfaction was measured by the five dimensions of service quality and was analyzed using percentage and Likert scale. The results showed the average percentage of interpretation score of $68 \%$ which means included in the category of satisfaction.
\end{abstract}

Keywords: The level of satisfaction, pharmaceutical service, RSUD Dr. Murjani Sampit

\section{PENDAHULUAN}

Kualitas pelayanan kesehatan adalah pelayanan kesehatan yang dapat menimbulkan kepuasan pada setiap pasien dimana tata cara penyelenggaraannya sesuai dengan standar dan kode etik yang telah ditetapkan. Kepuasan menjadi bagian penting dalam pelayanan kesehatan sebab kepuasan pasien tidak dapat dipisahkan dari kualitas pelayanan kesehatan. Jika ingin melakukan peningkatan kualitas pelayanan maka diperlukannya survei tingkat kepuasan pasien. Menurut Parasuraman et al, ada lima dimensi kualitas jasa untuk melihat kepuasan konsumen atau pasien yang dikenal dengan nama ServQual. Kelima dimensi tersebut meliputi kehandalan (reliability), ketanggapan (responsiveness), keyakinan (confidence), empati (emphaty) dan bukti langsung (tangible) (Daulay, 2015).

Kepuasan konsumen adalah tanggapan pelanggan atau pengguna jasa untuk setiap pelayanan yang diberikan. Kepuasan konsumen atau kepuasan pasien dapat dikatakan sebagai tolak ukur untuk mengetahui kualitas pelayanan yang diberikan oleh Rumah Sakit atau Instalasi Farmasi
Rumah Sakit. Jika kepuasan pasien yang dihasilkan baik, berarti pelayanan yang disuguhkan oleh Instalasi Farmasi Rumah Sakit tersebut juga sangat baik. Namun jika kepuasan pasien yang dihasilkan tidak baik, berarti perlu dilakukan evaluasi khusus tentang pelayanan Instalasi Farmasi Rumah Sakit yang dilakukan oleh Rumah Sakit tertentu.

Salah satu pelayanan kesehatan di Rumah Sakit adalah Instalasi Farmasi Rumah Sakit. Berdasarkan Undang-Undang Nomor 44 Tahun 2009 tentang Rumah Sakit, Instalasi Farmasi Rumah Sakit yang mempunyai peranan penting dalam mengelola perbekalan farmasi, pelayanan kefarmasian dalam penggunaan obat dan alat kesehatan serta pelayanan farmasi klinik. Menurut Peraturan Pemerintah Nomor 5I Tahun 2009 tentang Pekerjaan Kefarmasian menyatakan bahwa pelayanan kefarmasian adalah suatu pelayanan langsung dan bertanggung jawab kepada pasien yang berkaitan dengan sediaan farmasi, dengan maksud mencapai hasil yang pasti untuk rneningkatkan mutu kehidupan pasien serta menegaskan bahwa pekerjaan kefarmasian pada pelayanan farmasi dilakukan oleh Apoteker. 
Pelayanan kefarmasian yang baik adalah pelayanan yang berorientasi langsung dalam proses penggunaan obat, bertujuan menjamin keamanan, efektifitas dan kerasionalan penggunaan obat dengan menerapkan ilmu pengetahuan dan fungsi dalam perawatan pasien. Tuntutan pasien dan masyarakat akan mutu pelayanan kefarmasian mengharuskan adanya perubahan paradigma pelayanan dari paradigma lama yang berorientasi pada produk obat, menjadi paradigma baru yang berorientasi pada pasien (Bertawati, 2013).

RSUD Dr. Murjani Sampit adalah Rumah Sakit terbesar di Kabupaten Kotawaringin Timur, terletak di Jalan H.M. Arsyad No. 65 Sampit. Rumah Sakit milik pemerintah daerah ini menjadi tumpuan dan harapan masyarakat Kabupaten Kotawaringin Timur untuk mendapatkan pelayanan kesehatan.

Dalam hal ini peningkatan mutu pelayanan di bidang kesehatan dianggap penting oleh RSUD Dr. Murjani Sampit karena merupakan salah satu wujud dan bentuk tanggung jawab untuk turut serta dalam tugas meningkatkan derajat kesehatan yang optimal sehingga berbagai upaya perlu dilakukan untuk meningkatkan mutu pelayanan kesehatan. Salah satu faktor penunjang pelayanan Rumah Sakit adalah Instalasi Farmasi Rumah Sakit. Instalasi Farmasi Rumah Sakit adalah satu-satunya unit di Rumah Sakit yang bertugas dan bertanggung jawab sepenuhnya pada pengelolaan obat atau lebih tepatnya kegiatan kefarmasian.

Berdasarkan observasi langsung yang dilakukan, banyak pasien yang berkunjung ke Instalasi Farmasi RSUD Dr. Murjani Sampit mengeluh karena ketidakpahaman mengenai alur pelayanan kesehatan. Hal ini dikarenakan tidak tersedianya fasilitas visual penunjuk alur pelayanan kesehatan. Selain itu, terdapat keluhan pasien terhadap ketersediaan obat di Instalasi Farmasi Rumah Sakit. Berdasarkan hal tersebut maka peneliti tertarik melakukan penelitian ini. Penelitian ini bertujuan untuk mengetahui tingkat kepuasan pasien terhadap pelayanan kefarmasian di RSUD Dr. Murjani Sampit.

\section{METODOLOGI}

\section{Metode Penelitian}

I. Populasi dan Sampel

Populasi dalam penelitian ini adalah pasien rawat jalan yang mendapatkan pelayanan farmasi di Instalasi Farmasi RSUD Dr. Murjani Sampit dengan jumlah rata-rata 7.067 pasien perbulannya. Jumlah sampel dalam penelitian ini ditentukan menggunakan rumus Slovin, yaitu sebesar 100 responden.
2. Teknik Pengambilan Sampel

Pengambilan sampel pada penelitian ini berdasarkan teknik accidental sampling. Teknik ini didasarkan pada pengambilan sampel yang dilakukan dengan mengambil sampel yang kebetulan ada pada saat sedang melakukan penelitian (Sani, 2016). Dalam penelitian ini sampel/responden yang dipilih adalah pasien rawat jalan atau pendamping pasien rawat jalan dan bagian poliklinik yang mendapat pelayanan farmasi dan dianggap peneliti mampu berkomunikasi dengan baik sehingga dapat mempertanggungjawabkan apa yang telah ia kemukakan (Supardi, 20I4).

\section{Definisi Operasional}

Definisi operasional pada penelitian ini adalah:

a. Pasien: Seseorang yang berobat jalan dan mendapatkan pelayanan farmasi di Instalasi Farmasi RSUD Dr. Murjani Sampit.

b. Pelayanan: Semua jenis pelayanan farmasi yang diberikan oleh petugas farmasi di Instalasi Farmasi RSUD Dr. Murjani Sampit kepada pasien yang mendapat pelayanan.

c. Kepuasan: Tingkat keadaan yang dirasakan pasien yang merupakan hasil dari membandingkan penampilan atau hasil produk yang dirasakan dalam hubungannya dengan harapan pasien.

d. Tingkat Kepuasan: Jika penampilan pelayanan sangat kurang dari harapan, pasien tidak puas maka diberi skor I. Jika penampilan pelayanan kurang dari harapan, pasien kurang puas maka diberi skor 2. Jika penampilan pelayanan cukup dari harapan, pasien cukup puas maka diberi skor 3. Jika penampilan pelayanan sesuai dengan harapan, pasien puas maka diberi skor 4. Dan jika penampilan pelayanan melebihi harapan, pasien sangat puas maka diberi skor 5.

4. Instrumen Penelitian

Instrumen dalam penelitian ini adalah kuesioner yang telah divalidasi.

5. Teknik Pengumpulan Data

Teknik pengumpulan data yang digunakan adalah data primer dan data sekunder. Data primer diperoleh melalui kuesioner yang disebarkan kepada responden yang menjadi subjek penelitian. Data sekunder diperoleh dari bagian rekam medik untuk mengetahui jumlah kunjungan pasien rawat jalan. 


\section{Analisis Data}

Data yang dikumpulkan kemudian dibuat dalam bentuk tabulasi dan dianalisis menggunakan rumus persentase. Analisis skor tingkat kepuasan pada penelitian ini menggunakan format jawaban Skala Likert, yang memungkinkan pasien menjawab dalam berbagai tingkatan (I-5) dimana setiap jawaban diberi bobot nilai dengan ketentuan sebagai berikut: skor 5 bila jawaban "sangat puas", skor 4 bila jawaban "puas", skor 3 bila jawaban "cukup puas", skor 2 bila jawaban "kurang puas", dan skor I bila jawaban "tidak puas". Kriteria interpretasi skor menurut Skala Likert dalam pengukuran tingkat kepuasan sebagai berikut: angka $0 \%-20 \%=$ Tidak Puas, angka $21 \%$ $40 \%=$ Kurang Puas, angka $41 \%-60 \%=$ Cukup Puas, angka $61 \%-80 \%=$ Puas, dan angka $81 \%-100 \%=$ Sangat Puas.

\section{HASIL DAN PEMBAHASAN}

\section{Karakteristik Responden}

Karakteristik responden/pasien pada penelitian ini dibagi ke dalam 6 kelompok yaitu umur, jenis kelamin, pendidikan, pekerjaan, penghasilan dan kunjungan di Instalasi Farmasi RSUD Dr. Murjani Sampit. Berdasarkan penelitian yang dilakukan persentase responden terbanyak berdasarkan usia adalah usia 26-35 tahun (44\%). Dari hasil data persentase responden terbanyak berdasarkan tingkat Pendidikan pada penelitian ini adalah tingkat Sekolah Menengah Atas dengan jumlah 37 responden (37\%), sedangkan dari hasil persentase responden terbanyak berdasarkan Pekerjaan adalah Pegawai Swasta dengan jumlah 28 responden (28\%). Dari hasil data persentase responden terbanyak berdasarkan Penghasilan pada penelitian ini adalah penghasilan I-5 Juta, sedangkan hasil persentase responden terbanyak berdasarkan Kunjungan adalah pasien yang berkunjung $>5 \mathrm{kali}$. Hal ini disebabkan pasien yang datang adalah pasien lama yang sudah sering berobat ke Instalasi Farmasi RSUD Dr. Murjani Sampit.

\section{Tingkat Kepuasan}

Secara keseluruhan, dari hasil penelitian dapat dikatakan bahwa tingkat kepuasan pasien terhadap pelayanan secara umum di Instalasi Farmasi RSUD Dr. Murjani Sampit termasuk dalam kategori puas, berdasarkan kriteria interpretasi skor menurut Skala Likert (Tabel I).

Tabel I. Gambaran Tingkat Kepuasan

\begin{tabular}{clccc}
\hline No & \multicolumn{1}{c}{ Dimensi } & $\begin{array}{c}\text { Jumlah } \\
\text { Skor }\end{array}$ & $\begin{array}{c}\text { Persentase } \\
(\%)\end{array}$ & Kriteria \\
\hline I & $\begin{array}{l}\text { Kehandalan } \\
\text { (reliability) }\end{array}$ & 328 & 65,6 & Puas \\
2 & $\begin{array}{l}\text { Ketanggapan } \\
\text { (responsiveness) }\end{array}$ & 338 & 67,6 & Puas \\
\hline
\end{tabular}

\begin{tabular}{clccc}
\hline 3 & $\begin{array}{l}\text { Keyakinan } \\
\text { (confidence) }\end{array}$ & 361 & 72,2 & Puas \\
4 & $\begin{array}{l}\text { Empati } \\
\text { (emphaty) }\end{array}$ & 333 & 66,6 & Puas \\
\hline & $\begin{array}{l}\text { Bukti Langsung } \\
\text { (tangible) }\end{array}$ & 343 & 68,6 & Puas \\
\hline & Rata-Rata & 340 & 68 & Puas \\
\hline
\end{tabular}

Pada dimensi pertama tentang kehandalan terdiri dari 4 (empat) pernyataan yaitu pernyataan I, 2, 3 dan 4. Dimensi ini bertujuan untuk mengetahui apakah pasien puas terhadap pelayanan kefarmasian di RSUD Dr. Murjani Sampit tentang kecepatan pelayanan obat, obat tersedia dengan lengkap, petugas Apotek melayani dengan ramah dan tersenyum dan selalu siap membantu. Indeks tingkat kepuasan pada dimensi ini di Instalasi Farmasi RSUD Dr. Murjani Sampit rata-rata sebesar $65,6 \%$ yang artinya puas (Tabel II). Berdasarkan Peraturan Menteri Kesehatan Republik Indonesia Nomor 72 Tahun 2016 tentang Standar Pelayanan Kefarmasian di Rumah Sakit, penyelenggaraan pelayanan kefarmasian di Rumah Sakit harus menjamin ketersediaan sediaan farmasi dan sumber daya manusia yang memberikan pelayanan kefarmasian dengan baik.

Tabel II. Dimensi I, Kehandalan (reliability)

\begin{tabular}{clccc}
\hline No & \multicolumn{1}{c}{$\begin{array}{c}\text { Jenis } \\
\text { Pelayanan }\end{array}$} & $\begin{array}{c}\text { Jumlah } \\
\text { Skor }\end{array}$ & $\begin{array}{c}\text { Persentase } \\
(\%)\end{array}$ & Kriteria \\
\hline I & $\begin{array}{l}\text { Kecepatan } \\
\text { pelayanan obat } \\
\text { Obat tersedia } \\
\text { dengan lengkap }\end{array}$ & 305 & 61 & Puas \\
3 & $\begin{array}{l}\text { Petugas Apotek } \\
\text { melayani dengan } \\
\text { ramah dan } \\
\text { tersenyum }\end{array}$ & 331 & 66,2 & Puas \\
4 & $\begin{array}{l}\text { Petugas Apotek } \\
\text { selalu siap } \\
\text { membantu }\end{array}$ & 329 & 65,8 & Puas \\
\hline & & & & \\
\hline & Rata-Rata & 328 & 65,6 & Puas \\
\hline
\end{tabular}

Pada dimensi kedua tentang ketanggapan terdiri dari 4 (empat) pernyataan yaitu pernyataan I, 2, 3 dan 4. Dimensi ini bertujuan mengetahui apakah pasien puas terhadap pelayanan Kefarmasian di RSUD Dr. Murjani Sampit tentang petugas Apotek cepat tanggap terhadap keluhan pasien, petugas Apotek mampu memberikan penyelesaian masalah yang dihadapi pasien, terjadi komunikasi yang baik antara petugas Apotek dengan pasien dan pasien mendapatkan informasi yang jelas dan mudah dimengerti tentang resep yang ditebusnya. Indeks tingkat kepuasan di Instalasi Farmasi RSUD Dr. Murjani Sampit rata-rata sebesar 67,6\% yang artinya puas (Tabel III). Berdasarkan Peraturan Menteri Kesehatan Republik Indonesia Nomor 72 Tahun 2016 tentang Standar Pelayanan Kefarmasian di Rumah Sakit, tenaga kefarmasian mampu melakukan komunikasi dengan pasien atau keluarga pasien. 
Tabel III. Dimensi 2, Ketanggapan (responsiveness)

\begin{tabular}{|c|c|c|c|c|}
\hline No & $\begin{array}{c}\text { Jenis } \\
\text { Pelayanan }\end{array}$ & $\begin{array}{l}\text { Jumlah } \\
\text { Skor }\end{array}$ & $\begin{array}{c}\text { Persentase } \\
\text { (\%) }\end{array}$ & Kriteria \\
\hline I & $\begin{array}{l}\text { Petugas Apotek } \\
\text { cepat tanggap } \\
\text { terhadap } \\
\text { keluhan pasien }\end{array}$ & 326 & 65,2 & Puas \\
\hline 2 & $\begin{array}{l}\text { Petugas Apotek } \\
\text { mampu } \\
\text { memberikan } \\
\text { penyelesaian } \\
\text { terhadap } \\
\text { masalah yang } \\
\text { dihadapi pasien }\end{array}$ & 330 & 66 & Puas \\
\hline 3 & $\begin{array}{l}\text { Terjadi } \\
\text { komunikasi yang } \\
\text { baik antara } \\
\text { petugas Apotek } \\
\text { dengan pasien }\end{array}$ & 339 & 67,8 & Puas \\
\hline 4 & $\begin{array}{l}\text { Pasien } \\
\text { mendapatkan } \\
\text { informasi yang } \\
\text { jelas dan mudah } \\
\text { dimengerti } \\
\text { tentang } \\
\text { resep/obat yang } \\
\text { di tebusnya }\end{array}$ & 358 & 71,6 & Puas \\
\hline & Rata-Rata & 338 & 67,6 & Puas \\
\hline
\end{tabular}

Pada dimensi ketiga tentang keyakinan terdiri dari 3 (tiga) pernyataan yaitu pernyataan I, 2 dan 3. Dimensi ini bertujuan mengetahui kepuasan pasien terhadap pelayanan Kefarmasian di RSUD Dr. Murjani Sampit tentang petugas apotek mempunyai pengetahuan dan keterampilan yang baik dalam bekerja, obat yang diperoleh terjamin kualitasnya dan obat yang diberikan sesuai dengan yang diminta. Indeks tingkat kepuasan di Instalasi Farmasi RSUD Dr. Murjani Sampit rata-rata sebesar $72,2 \%$ yang artinya puas (Tabel IV). Berdasarkan Peraturan Menteri Kesehatan Republik Indonesia Nomor 72 Tahun 2016 tentang Standar Pelayanan Kefarmasian di Rumah Sakit, tenaga kefarmasian harus memberikan informasi dan edukasi penggunaan obat yang baik berdasarkan resep kepada pasien atau keluarga pasien, sehingga obat yang diberikan sesuai dengan resep dan obat terjamin kualitasnya.

Tabel IV. Dimensi 3, Keyakinan (confidence)

\begin{tabular}{clccc}
\hline No & $\begin{array}{c}\text { Jenis } \\
\text { Pelayanan }\end{array}$ & $\begin{array}{c}\text { Jumlah } \\
\text { Skor }\end{array}$ & $\begin{array}{c}\text { Persentase } \\
(\%)\end{array}$ & Kriteria \\
\hline I & $\begin{array}{l}\text { Petugas Apotek } \\
\text { mempunyai } \\
\text { pengetahuan dan } \\
\text { keterampilan } \\
\text { yang baik dalam } \\
\text { bekerja } \\
\text { Obat yang } \\
\text { diperoleh } \\
\text { terjamin } \\
\text { kualitasnya } \\
\text { Obat yang } \\
\text { diberikan sesuai }\end{array}$ & 349 & 69,8 & Puas \\
\hline & 361 & 72,2 & Puas \\
\hline
\end{tabular}

\begin{tabular}{llll}
\hline $\begin{array}{l}\text { dengan yang } \\
\text { diminta }\end{array}$ & & & \\
\hline Rata-Rata & 361 & 72,2 & Puas \\
\hline
\end{tabular}

Pada dimensi keempat tentang empati terdiri dari 3 (tiga) pernyataan yaitu pernyataan I, 2 dan 3 . Dimensi ini bertujuan untuk mengetahui apakah pasien puas terhadap pelayanan Kefarmasian di RSUD Dr. Murjani Sampit tentang petugas Apotek memberikan perhatian terhadap keluhan pasien, petugas apotek memberikan pelayanan kepada semua pasien tanpa memandang status sosial dan pasien merasa nyaman selama menunggu obat. Indeks tingkat kepuasan di Instalasi Farmasi RSUD Dr. Murjani Sampit rata-rata sebesar $66,6 \%$ yang artinya puas (Tabel V). Berdasarkan Peraturan Pemerintah Nomor 5 I Tahun 2009 tentang Pekerjaan Kefarmasian bahwa Tenaga Teknis Kefarmasian memberikan perlakuan sama dengan tidak membedakan suku, bangsa, agama, status sosial dan ras.

Tabel V. Dimensi 4, Empati (emphaty)

\begin{tabular}{clccc}
\hline No & $\begin{array}{c}\text { Jenis } \\
\text { Pelayanan }\end{array}$ & $\begin{array}{c}\text { Jumlah } \\
\text { Skor }\end{array}$ & $\begin{array}{c}\text { Persentase } \\
(\%)\end{array}$ & Kriteria \\
\hline I & $\begin{array}{l}\text { Petugas Apotek } \\
\text { memberikan } \\
\text { perhatian } \\
\text { terhadap } \\
\text { keluhan pasien }\end{array}$ & 328 & 65,6 & Puas \\
2 & & & \\
$\begin{array}{l}\text { Petugas Apotek } \\
\text { memberikan } \\
\text { pelayanan } \\
\text { kepada } \\
\text { semua pasien } \\
\text { tanpa } \\
\text { memandang } \\
\text { status sosial }\end{array}$ & 343 & 68,6 & Puas \\
$\begin{array}{l}\text { Pasien merasa } \\
\text { nyaman selama } \\
\text { menunggu obat }\end{array}$ & 328 & 65,6 & \\
\hline Rata-Rata & 333 & 66,6 & Puas \\
\hline
\end{tabular}

Pada dimensi kelima tentang bukti langsung terdiri dari 4 (empat) pernyataan yaitu pernyataan I, 2, 3 dan 4. Dimensi ini bertujuan untuk mengetahui apakah pasien puas terhadap pelayanan Kefarmasian di RSUD Dr. Murjani Sampit tentang Apotek terlihat bersih dan rapi, kenyamanan ruang tunggu, penataan eksterior dan interior ruangan dan petugas Apotek berpakaian bersih dan rapi. Indeks tingkat kepuasan di Instalasi Farmasi RSUD Dr. Murjani Sampit rata-rata sebesar $68,6 \%$ yang artinya puas (Tabel VI). Berdasarkan Peraturan Menteri Kesehatan Republik Indonesia Nomor 72 Tahun 2016 tentang Standar Pelayanan Kefarmasian di Rumah Sakit, sebaiknya pada sarana kefarmasian di Rumah Sakit memiliki fasilitas ruang yang memadai dalam hal kualitas dan kuantitas agar dapat menunjang fungsi dan proses pelayanan kefarmasian. Salah satu fasilitas penunjang adalah ruang tunggu, ruang tunggu haruslah terlihat rapi baik interior maupun eksterior. 
Tabel VI. Dimensi 5, Bukti Langsung (tangible)

\begin{tabular}{clccc}
\hline No & $\begin{array}{c}\text { Jenis } \\
\text { Pelayanan }\end{array}$ & $\begin{array}{c}\text { Jumlah } \\
\text { Skor }\end{array}$ & $\begin{array}{c}\text { Persentase } \\
(\%)\end{array}$ & Kriteria \\
\hline 1 & $\begin{array}{l}\text { Apotek terlihat } \\
\text { bersih dan rapi }\end{array}$ & 345 & 69 & Puas \\
2 & $\begin{array}{l}\text { Kenyamanan } \\
\text { ruang tunggu }\end{array}$ & 332 & 66,4 & Puas \\
3 & $\begin{array}{l}\text { Penataan } \\
\text { eksterior dan } \\
\text { interior ruangan }\end{array}$ & 322 & 64,4 & Puas \\
4 & $\begin{array}{l}\text { Petugas apotek } \\
\text { berpakaian } \\
\text { bersih dan rapi }\end{array}$ & 373 & 74,6 & Puas \\
\hline & Rata-Rata & 343 & 68,6 & Puas \\
\hline
\end{tabular}

\section{KESIMPULAN}

Berdasarkan hasil penelitian, diketahui tingkat kepuasan pasien dengan rata-rata persentase interpretasi skor sebesar $68 \%$ yang artinya masuk dalam kategori puas. Kedepannya, perlu dilakukan evaluasi tingkat kepuasan setiap saat untuk perkembangan dan kemajuan pelayanan di Instalasi Farmasi RSUD dr. Murjani Sampit, karena kepuasan pasien setiap saat akan berubah seiring dengan kebutuhan yang diinginkan oleh pasien tersebut.

\section{DAFTAR PUSTAKA}

Anisah, Khotimah, S. dan Yanti, A.H. 2014. Aktivitas antibakteri ekstrak rimpang jeringau (Acoros calamus L.) terhadap pertumbuhan Staphylococcus aureus dan Echerichia coli. Jurnal Protobiont. 3(3): I.

Bertawati. 2013. Profil pelayanan kefarmasian dan kepuasan konsumen apotik di Kecamatan Adiwerna Kota Tegal. Jurnal Ilmiah Mahasiswa Universitas Surabaya. 2(2):I-II.

Departemen Kesehatan Republik Indonesia. 2009. Peraturan Pemerintah Republik Indonesia Nomor $5 \mathrm{I}$ Tahun 2009 Tentang Pekerjaan Kefarmasian. Jakarta.

Departemen Kesehatan Republik Indonesia. 2009. UndangUndang Republik Indonesia Nomor 44 tentang Rumah Sakit. Jakarta.

Kementerian Kesehatan Republik Indonesia. 2016. Peraturan Menteri Kesehatan Republik Indonesia Nomor 72 Tahun 2016 tentang Standar Pelayanan Kefarmasian di Rumah Sakit. Jakarta.

Daulay, M.A. 20I5. Tingkat kepuasan pasien rawat jalan peserta BPS kesehatan terhadap pelayanan kefarmasian di dua puskesmas di Kota Medan. Skripsi, Fakultas Farmasi, Universitas Sumatera Utara.

Sani, F. 2016. Metodologi Penelitian Farmasi Komunitas dan Eksperimental Edisi I Cetak I. Yogyakarta, Deepublish.
Supardi, Sudibyo dan Surahman. 2014. Metodelogi Penelitian Untuk Mahasiswa Farmasi. Jakarta, Trans Indo Media. 